REVISTA DE DERECHO UNED, NÚM. 27, 2021

\title{
ANÁLISIS DEL RÉGIMEN DE LAS OBLIGACIONES CONEXAS EN LOS PROCEDIMIENTOS TRIBUTARIOS ${ }^{1}$.
}

\author{
ANALYSIS OF THE REGIME OF RELATED OBLIGATIONS \\ IN THE TAX PROCEDURES.
}

Adela de la LuZ de la Osa Fondón

Licenciada en Derecho y Graduada en Ciencias Jurídicas de la Administraciones públicas. (Universidad Nacional de Educación a distancia)

Sumario: I. Introducción. II. Antecedentes y finalidad de la reforma. III. Concepto y caracteres de las obligaciones conexas. II.A. Definición legal. II.B. Características. II.C. Ámbito de aplicación. IV. Efectos de las obligaciones conexas sobre la interrupción de la prescripción. V. Las obligaciones conexas en los procedimientos de comprobación. V.A. Las obligaciones conexas en los VI. Obligaciones conexas en el recurso de reposición. Concepto, objeto y naturaleza. VII. Obligaciones conexas en las reclamaciones económico-administrativas. VIII. Conclusiones. IX. Bibliografía. IX.A. Textos. IX.B. Materiales Telemáticos. IX.C. Revistas.

Resumen. La publicación de la Ley 34/2015 de modificación parcial de la Ley General Tributaria introduce un concepto nuevo - las obligaciones conexas - que han venido a revolucionar los procedi-

1 El presente trabajo se ha efectuado a razón de la Ley 34/2015, de 21 de septiembre, de modificación parcial de la ley 58/2003, General Tributaria, con la finalidad de dar a conocer los posibles los efectos que han producido, en general en todo el sistema tributario español y en especial en las obligaciones conexas y cómo se percibirán en los procedimientos de gestión e inspección, así como en las económico-administrativas y recurso de reposición. 
mientos tributarios, por alterar significativamente el instituto de la prescripción. Este concepto, ofrece unos efectos de gran relevancia, como la interrupción del plazo de prescripción en las obligaciones conexas.

Palabras clave: Impuestos, Obligaciones Conexas, Interrupción de la prescripción.

Abstract. The publication of Law 34/2015 of partial modification of the General Tax Law introduces a new concept - related obligations - that have come to revolutionize tax procedures, by significantly altering the statute of limitations. This concept offers very relevant effects, such as the interruption of the limitation period in related obligations.

Keywords: Taxes, Related obligations, Interruption of the limitation period.

Recepción original: 25-4-2020

Aceptación original: 10-7-2020

\section{INTRODUCCIÓN}

Hasta la entrada en vigor de la Ley 34/2015 de modificación parcial de la Ley General Tributaria podría darse el caso que cuando la Administración intentaba regularizar una obligación tributaria, que estaba relacionada con otra del mismo contribuyente, no pudiera hacerlo por estar la deuda prescrita. Se podían generar situaciones antagónicas; sobreimposición del administrado y, por consiguiente, perjuicio del contribuyente, aunque no siempre, ya que podían producirse escenarios en los que se pudiera causar nula tributación del administrado, resultando, en este supuesto, el correspondiente perjuicio de la Agencia Tributaria por no poder revisarlo por prescripción de la acción. Por ende, el perjuicio se podía causar en ambas partes2: "El primer supuesto se produce, por ejemplo, cuando se regulariza al alza un período para incluir una renta o ingreso que el obligado autoliquidó y consideró imputable a otro período impositivo posterior que, en el momento de notificarse la primera regularización, se encuentra prescrito a efectos de solicitar la devolución de ingresos indebidos.

2 Cordero González, Eva $\mathrm{M}^{\mathrm{a}}$, "La interrupción de la prescripción en relación con las obligaciones conexas tras la reforma de la Ley General Tributaria por Ley 34/2015. Revista española de Derecho Financiero núm. 170/2016. Editorial Civitas, SA. Pág. 2-20. 
Si un contribuyente presenta una reclamación económico administrativa en 2014, sobre el ejercicio 2011 y esa reclamación no se resuelve hasta 2018, se podría decir que los ejercicios 2012 y 2013, habrían estado prescritos, sin embargo, tras la reforma, dejarían de estarlo gracias a la interrupción de la prescripción.

El segundo concurre, por ejemplo, cuando también con motivo de una discrepancia en la imputación temporal de determinadas rentas, producida una regularización que comprende varios períodos a ingresar y devolver, se recurre solo la liquidación al alza, que es estimada. La nueva disposición trata de evitar que la prescripción impida a la Administración modificar las liquidaciones a devolver y exigir la deuda en el período procedente según la resolución administrativa".

Para dar solución a la situación planteada, se introduce un nuevo apartado 9 en el artículo 68 de la LGT, referente a la interrupción del plazo de prescripción. Así, la reforma de la LGT define las obligaciones conexas como "aquellas en las que algunos de sus elementos resulten afectados o se determinen en función de los correspondientes a otra obligación o período distinto. El art.68.9 LGT lo que viene a decirnos es que la interrupción de la prescripción operará cuando existan obligaciones conexas(vinculadas-relacionadas), aun cuando sean posteriores a la ya regularizada, y produzcan o haya de producirse una tributación distinta de aquellos criterios en los que se basa la regularización. Se daba por sentado, que el criterio de la Administración había de primar sobre el del contribuyente. De esta manera, la presunción de legalidad de la actuación administrativa prima sobre la suspensión cautelar. GÓMEZ TABOADA ${ }^{3}$ asevera al respecto:" Por la vía de modificar la prescripción, el poder Legislativo ha dado carta de naturaleza a la prevalencia de la autotutela administrativa frente al derecho fundamental a la tutela judicial efectiva al consagrar, ya legalmente, que la presunción de legalidad del acto no se vea afectada por la suspensión cautelar del mismo". TABOADA, afirma que "esta Ley (...) introduce un claro sesgo favorable a las ya exorbitantes facultades de la Administración en detrimento de los derechos de los administrados, siendo paradigma de ello el régimen previsto para las obligaciones conexas en las que la presunción de legalidad de la actuación administrativa prima sobre la suspensión cautelar (manifestación obvia del fundamental derecho a la tutela judicial efectiva).

3 Gómez Taboada, J.: "Las obligaciones tributarias conexas han venido para quedarse", en El notario del siglo XXI, núm. 69, 2016. Referenciado en el resumen del artículo. 
GÓMEZ TABOADA nos ayuda a comprender sus afirmaciones a través de un sencillo supuesto práctico, pensemos, por ejemplo, en una persona física a la que la Agencia Tributaria (AEAT) le cuestiona el carácter habitual de su vivienda, sobre la que existe la carga un préstamo hipotecario. Consecuencia de ello, la agencia le niega la deducibilidad fiscal de las cuotas de su préstamo cuando aún le quedan muchos años de amortización; o una empresa cuyas cuotas de IVA a compensar son modificadas. En estos y otros casos más, se genera esa relación entre una obligación tributaria, que es el objeto de regularización por la AEAT, y otras, las puedan resultar posteriores -e, incluso, futuras- autoliquidadas por el contribuyente.

Hasta el momento de la reforma, y salvo contadas excepciones, los efectos interruptivos de las actuaciones administrativas de comprobación quedaban determinados por el alcance del acuerdo de inicio del procedimiento. De tal forma que podemos destacar diversas situaciones:

- Cuando se trate de actuaciones de alcance general, la prescripción del derecho a determinar la deuda tributaria se veía interrumpida en relación con las obligaciones y períodos en él indicados. Este alcance se manifestaba también en cualquiera actuación realizada en el marco del procedimiento, aunque vinieran referidas sólo a alguno de los conceptos en él incluidos.

- En el caso de que se trate de actuaciones de carácter parcial, el acuerdo de inicio perdía relevancia, considerando tanto la jurisprudencia como la doctrina administrativa que los efectos interruptivos de la prescripción se extendían a la totalidad de la obligación tributaria.

El concepto de obligaciones conexas, ofrece unos efectos de gran relevancia, como se ha ido adelantando, la interrupción del plazo de prescripción en las obligaciones conexas. Los efectos producidos se percibirán en los procedimientos de gestión e inspección, así como en las económico-administrativas y recurso de reposición.

El nuevo apartado 9 del artículo 68 de la LGT altera sensiblemente el esquema anterior a la reforma, pues a partir de ahora la regularización de determinadas obligaciones y períodos interrumpirá también el derecho a liquidar y el derecho a solicitar la devolución de ingresos indebidos de otras obligaciones que se consideren conexa con la primera y no se hallen incluidas en el acuerdo de iniciación, ni siquiera, a falta de desarrollo reglamentario, identificadas como tales en la liquidación resultante del procedimiento. Para 
que se produzca el efecto interruptivo, sólo es necesario que se trate de obligaciones del propio obligado cuyos elementos resulten afectados o se determinen en función de los correspondientes a otra obligación o período distinto y siempre que «en ellas se produzca o haya de producirse una tributación distinta a consecuencia de la aplicación de los criterios o elementos en que se fundamente la regularización de la primera». Los recursos o reclamaciones planteados frente a la liquidación inicial, también interrumpirán también el derecho a determinar la deuda y a solicitar la devolución de ingresos indebidos en relación con otras obligaciones conexas.

A pesar que la reforma ha traído más luz a cuestiones que , en muchos casos resultaban injustas, no es menos cierto que va a provocar una indefinición de la nueva regulación, dejando un puerta abierta a la posible interrupción, indiscriminada, de la prescripción para exigir cualesquiera otras obligaciones conectadas con la que está siendo objeto de regularización o sea impugnada por el obligado, sin que, en el momento de iniciarse las actuaciones o interponerse el recurso o reclamación, se tenga constancia de las que puedan verse afectadas.

Si la reforma pretendía «reforzar la seguridad jurídica y reducir la litigiosidad», según señala la Exposición de Motivos, en nuestra opinión produce precisamente el resultado contrario, teniendo en cuenta que la normativa elimina toda certeza en esta materia y será un foco inagotable de conflictividad, a la vista de la gran caustica que se abre en torno a esta problemática.

El presente trabajo pretende establecer las potenciales consecuencias de la reforma en diversos supuestos de "conexidad», incidiendo en el carácter total o parcial del efecto interruptivo de la prescripción en relación con otros posibles elementos de las obligaciones conexas no afectados por la regularización inicial o principal. Se apuntan también los problemas que plantea la conexidad en fase de revisión, tanto por lo que respecta a la impugnación y posible suspensión de la liquidación con efectos en otros períodos u obligaciones, como en relación con la ejecución de la resolución estimatoria del recurso o reclamación presentados que, de acuerdo con la modificación introducida en los artículos 225.3 y 239.7 de la LGT, afectará también al resto de obligaciones vinculadas con la primera.

A pesar de intentar dar a conocer las consecuencias de la reforma alrededor de las obligaciones conexas, quedan muchas cuestiones planteadas y aún muchas preguntas por responder. 


\section{ANTECEDENTES Y FINALIDAD DE LA REFORMA}

Siguiendo a la profesora CORDERO GONZÁLEZ ${ }^{4}$, la finalidad de la reforma ha sido la de eliminar las situaciones de doble imposición en perjuicio del obligado tributario o de nula tributación en detrimento de los intereses del erario público, que ha dado lugar la aplicación de las reglas ordinarias sobre la prescripción. El Consejo para la Defensa del Contribuyente había aludido a la primera de estas situaciones en las propuestas 33/1999 y 3/2007 que, a pesar del tiempo transcurrido, pueden considerarse como antecedentes de la reforma:

Para CORDERO GONZÁLEZ "La primera de las propuestas aborda los supuestos en los que, a consecuencia de una discrepancia en la aplicación de los criterios de imputación temporal, se llevan a un período posterior los ingresos declarados por el obligado en la autoliquidación del IRPF de un período anterior. Tras presentar reclamación económico-administrativa y resultar desestimada varios años después, se solicita la rectificación de la primitiva declaración al efecto de obtener la devolución de lo excesivamente ingresado, solicitud que es rechazada al considerarse prescrito este derecho". A este supuesto se refiere expresamente la memoria del análisis del impacto normativo de la nueva Ley, advirtiendo que se trata de «una situación cotidiana, meramente descriptiva de la casuística que pretende regularse», aunque aludiendo al caso más frecuente en el que el ingreso o cuota se considere obtenido en períodos anteriores al declarado por el contribuyente".

La propuesta 3/2007, continúa explicando CORDERO GONZÁLEZ, "se refiere también a los supuestos de la denominada tributación diferida por aplicación de incentivos fiscales que, retrasan la tributación de determinadas rentas a períodos posteriores a su obtención. En estos casos, el problema surge, cuando iniciado un procedimiento inspector en relación con un determinado período impositivo, se considera improcedente la aplicación del régimen de diferimiento, debiendo tributar la totalidad de la renta en el período regularizado. Al momento de emitirse la liquidación varios años después, el contribuyente puede encontrarse en una situación jurídica de inseguridad e indefensión derivada de la imposibilidad de solicitar la devolución de los ingresos indebidos por los tributos pa-

4 Cordero González, Eva $\mathrm{M}^{\mathrm{a}}$." La interrupción de la prescripción en relación con las obligaciones conexas tras la reforma de la Ley General Tributaria por Ley 34/2015". Revista española de Derecho Financiero num.170/2016 parte Estudios Editorial Civitas, SA, Pamplona. 2016. BIB 2016\2649. Págs.1-27. 
gados en los períodos posteriores en los que aplicó el diferimiento, devolución que, por otro lado, ya se encontraría prescrita como consecuencia de la aplicación de su propio plazo de prescripción no interrumpido".

Concluye CORDERO GONZÁLEZ que "Lo que pretende la propuesta del Consejo, es la extensión de los efectos interruptivos de la prescripción de una obligación a los de las obligaciones conexas por aplicación de un régimen de diferimiento. Así, el derecho a la devolución de ingresos indebidos habría de considerarse interrumpido por cualquier actuación de la Administración tributaria tendente a la determinación de la deuda en relación con los elementos de la obligación tributaria que dio lugar al diferimiento".

\section{CONCEPTO Y CARACTERES DE LAS OBLIGACIONES CONEXAS.}

\section{A. Definición legal.}

¿Qué son las obligaciones tributarias conexas? ¿Cómo pueden definirse?

La respuesta a estas preguntas las podemos encontrar en la propia LGT y más concretamente en el segundo párrafo del apartado 9 del artículo 68 de la Ley: "Se entenderá por obligaciones tributarias conexas aquellas en las que alguno de sus elementos resulte afectado o se determinen en función de los correspondientes a otra obligación o período distinto".

Sin embargo, al analizar la definición que la LGT facilita de las mismas, podemos descubrir una serie de términos que si bien son indeterminados, da la sensación de que es posible descomponer las obligaciones tributarias en elementos (TEJERIZO J.M.5). J.M. Tejerizo expone que si, como consecuencia de la actuación administrativa, se ha producido la interrupción de la prescripción y como consecuencia de ella se altera la calificación de un elemento tributario, será la nueva calificación, la que afecte a la exigencia de la cuota o al propio reconocimiento de la devolución en los tributos, cuando se trate del mismo obligado y sean conexos con el tributo alterado. Podemos señalar un par de comentarios para poder aclarar estos conceptos. GÓMEZ TABOADA, establece que "si la Agencia Tributaria (AEAT, en adelante) le cuestiona a una persona el carácter habitual de su vivienda, negándole la deducibilidad fiscal de las cuotas de su préstamo hipotecario cuando aún le quedan muchos años de amor- 
tización; o una empresa a la que la AEAT le minora sustancialmente su saldo de IVA a compensar en ejercicios sucesivos... En estos casos, lo que se genera es un vínculo entre una obligación tributaria (objeto de regularización por la AEAT) y otras (las posteriores -e, incluso, futuras- autoliquidadas por el contribuyente) $)^{6 ”}$.

\section{III.B. Características.}

Se define la conexión por dos vías diferentes:

Cuando venga reflejada por una referencia legal. En el caso de que algún elemento de una determinada obligación tributaria, podría llamarse principal, se determine en función de un elemento correspondiente a otra obligación tributaria, lo que parece reflejar es la existencia de una referencia legal relacionada con otra obligación tributaria. Esto podría pasar en el caso en que un sujeto realizará una transmisión de un determinado bien inmueble a otro sujeto, siendo que el transmitente, puede haber generado ganancias o pérdidas patrimoniales por esta operación (en el impuesto de las rentas de las personas físicas-IRPF) el adquirente, deberá de tributar por el Impuesto de Transmisiones Patrimoniales (TPO, en adelante).

En un momento determinado (siempre dentro del plazo de prescripción de la facultad de la Administración para realizar comprobaciones o inspecciones), la Administración Tributaria puede iniciar un procedimiento de comprobación del valor del bien transmitido, el cual se resuelve con una liquidación, en la que puede ver modificado el valor del bien y por ello verse afectado tanto en el TPO del adquirente, como IRPF del transmitente. La liquidación resultante del procedimiento administrativo, afecta tanto al que ha transmitido como al que ha adquirido el bien.

Cuando no viene reflejada en una referencia legal. Si se trata de un caso concreto, cuando algún elemento de una obligación tributaria resulte afectado por elementos correspondientes a otra obligación tributaria. En este caso no se deriva de una referencia normativa, sino de un caso concreto. Sobre un ingreso pueden existir dudas acerca de en qué ejercicio corresponde atribuirlo, sin embargo, no puede corresponder a ambos. También puede suceder que no exista preferencia de una obligación tributaria respecto de otra, sino que, ambas fueran del mismo rango, de tal forma que la que

6 Gómez Taboada, J.: "Las obligaciones tributarias conexas han venido para quedarse”, en El notario del siglo XXI, núm. 69, 2016. Pág. 1 y 2. 
primero se determine o se llegare a modificar, afectaría a la que se modificase en segundo lugar ${ }^{7}$.

\section{III.C. Ámbito de aplicación ${ }^{8}$.}

Para la determinación del ámbito de aplicación de las obligaciones conexas podemos destacar una doble delimitación: positiva y negativa.

Dentro de la delimitación positiva se encuentran aquellas obligaciones en las que sus elementos de cuantificación o exigibilidad se integren o queden afectados por los de otro período u obligación. Cuando la regulación se realice en relación con una de ellas y motive una tributación distinta en la conexa, ocasionando discrepancias en la imputación temporal o en el diferimiento de rentas.

Dentro de la delimitación negativa, encontraríamos aquellas obligaciones que se encuentren a cargo de terceros (no del mismo obligado tributario) y a cuenta de la obligación tributaria principal, como pueden ser las retenciones, cuya vinculación también puede provocar situaciones de enriquecimiento injusto, puesto que el propio artículo 68.9 LGT, se refiere a obligaciones tributarias conexas siempre que se trate del mismo obligado tributario. También quedarían fuera de esta norma, aquellos tributos cuyos hechos imponibles se consideran incompatibles, si afectan a sujetos distintos (IVA e ITPO), así como las regularizaciones relativas a operaciones vinculadas y dicha interrupción se extiende a los demás obligados por la misma (incluidos los responsables), por aplicación el artículo 68.8 de la LGT (CORDERO GONZÁLEZ)

La Ley prevé que la realización de actuaciones administrativas tendentes a comprobar, regularizar, liquidar, etc.... los actos del propio obligado tributario, terminarán en una liquidación de la deuda, provocando la interrupción de los plazos de prescripción, así mismo, la propia interposición de un recurso o reclamación, en relación con una obligación principal, determinará también la interrupción del

7 Cremades Schütz, M.: "Las obligaciones conexas antes de la Reforma de la Ley General Tributaria por la Ley 34/2015”, en Actualidad Jurídica Uría-Menéndez, núm. 42, 2016. Págs. 115-120.

8 Cordero González, Eva $\mathrm{M}^{\mathrm{a}}$." La interrupción de la prescripción en relación con las obligaciones conexas tras la reforma de la Ley General Tributaria por Ley 34/2015". Revista española de Derecho Financiero num.170/2016 parte Estudios Editorial Civitas, SA, Pamplona. 2016. BIB 2016 2649. Pág. 6-7. 
derecho a liquidar o a solicitar la devolución, en relación con las obligaciones conexas o vinculadas a la principal.

\section{EFECTOS DE LAS OBLIGACIONES CONEXAS SOBRE LA INTERRUPCIÓN DE LA PRESCRIPCIÓN.}

La prescripción ${ }^{9}$ no es más que la consecuencia del transcurso del plazo establecido en la Ley, sin que la Administración realice las actuaciones de comprobación sobre actos del administrado, dirigidas a la liquidación de la deuda tributaria (inactividad de la Administración) [Sentencia de 23 de mayo de 2006 (rec. cas. núm. 18/2001), FD Quinto], que equivale materialmente a una verdadera renuncia del poder público a investigar y regularizar la obligación tributaria de que se trate (ESEVERRI MARTÍNEZ)10.

Una de las cuestiones que más preocupación ha causado la modificación de la LGT, es la extensión de los efectos interruptivos de la prescripción a las obligaciones conexas. Afirma ESEVERRI MARTÍNEZ ${ }^{11}$ que la reforma de la LGT, por la Ley 34/2015, "contiene importantes novedades en materia de prescripción que pueden afectar a las obligaciones de devolución, por la posibilidad de rectificar autoliquidaciones de períodos prescritos, o cuando la Administración Tributaria regularice una obligación tributaria conexa, en virtud de una solicitud de rectificación de autoliquidación, presentada por el obligado tributario. La reforma también modifica el artículo 119.4 LGT relativo a las declaraciones complementarias y solicitudes de rectificación. Estas modificaciones suponen una variación sustancial de la posición del contribuyente ante la Administración”. ESEVERRI MARTÍNEZ continúa aseverando que "La solicitud de rectificación de autoliquidaciones tributarias podría plantear problemas si se refiere a períodos prescritos con incidencia en períodos no prescritos. Piénsese en la solicitud de rectificación de un préstamo suscrito hace veinte años cuyos intereses son superiores a los que el contribuyente venía deduciendo, o en la transmisión de un inmueble adquirido hace diez años que está siendo objeto de comprobación, cuyo valor de adquisición se pretende aumentar por el contribuyente debido a una mejora realizada en un ejercicio prescrito".

Otra novedad de la reforma de la LGT que se puede destacar, dentro del régimen de la prescripción tributaria, es la interrupción del derecho a liquidar y devolver, de las obligaciones conexas con causa en la interrupción, a la vez del derecho a liquidar otra dis- 
posición distinta pero relacionada con ellas ${ }^{12}$. Según podemos llegar a deducir de la jurisprudencia del Tribunal Supremo y Tribunal Económico Administrativo Central, la LGT dispone que la interrupción del derecho a liquidar una obligación tributaria principal, interrumpe, a su vez, los derechos a liquidar y devolver otras obligaciones tributarias conexas con ella, con la titularidad del mismo obligado tributario y siempre que los elementos regularizados en la primera de las obligaciones, resulten de aplicación a las segundas y consecuencia de ello se establezca una tributación distinta en ellas ${ }^{13}$. Todo esto, hace reflexionar sobre los efectos que produce la interrupción del plazo de prescripción del derecho a liquidar las obligaciones conexas (CORDERO GONZALEZ) ${ }^{14}$.

Para que se produzca la interrupción del plazo de prescripción del derecho a liquidar obligaciones conexas respecto de otra obligación relacionada con ella, deben de concurrir los requisitos siguientes:

- La regularización de la obligación tributaria que opera de punto de conexión con las restantes debe provocar en estas un régimen tributario distinto al que se les ha dado.

- La aplicación a las conexas de la obligación regularizada ha de solicitarse por el interesado, o aplicarse de oficio por la Administración Tributaria.

- Las actuaciones administrativas de liquidación en las obligaciones conexas han de limitarse a reproducir la regularización llevada a cabo en la obligación que con ellas se encuentre relacionadas.

- Si las obligaciones conexas han sido objeto de liquidación administrativa firme, los efectos preclusivos de su firmeza no impiden su regularización tributaria en los mismos términos en que lo fue la obligación con ellas relacionada.

El cómputo inicial del plazo de prescripción, queda interrumpido, como consecuencia de cualquier actuación administrativa o de particular, tendente al ejercicio de los derechos susceptibles de prescribir, con el efecto inmediato de que el plazo de prescripción se

12 Artículo 68.9 LGT

13 Sentencias del TS de 12 y 19 de diciembre de 211(rec. 364/2008 7 324/2008) en relación con la LGT de 1963 y Resolución del TEAC de 23 de julio de 2009 en relación con el artículo 68 de la vigente LGT.

${ }_{14}$ Cordero González, Eva $\mathbf{M}^{\mathrm{a}}$ "La interrupción de la prescripción en relación con las obligaciones conexas tras la reforma de la Ley General Tributaria por Ley 34/2015". BIB 2016\2649. Págs. 1-27. 
regenera en su integridad a partir de ese instante (art. 68 LGT). La prescripción se debe aplicar de oficio, aunque el obligado tributario haya realizado el pago de la deuda prescrita (art. 69 LGT) .Una vez ganada la prescripción, beneficiará por igual a todos los obligados al pago de la deuda tributaria ${ }^{15}$.

Según establece el Profesor TEJERIZO ${ }^{16}$," el artículo 68.9 LGT debe de ser aplicado a las modificaciones en la imputación temporal de los elementos de la obligación, puesto que produce, en realidad, una compensación de oficio durante el plazo de ingreso voluntario, entre las liquidaciones que deriven de la aplicación de las normas de los tributos implicados"

El artículo 68.9 LGT deja abierta la cuestión de determinar el momento a partir del cual tendrá lugar el efecto interruptivo, dado que:

Por una parte, se alude a la realización de actuaciones administrativas de comprobación, para que, en el régimen general de la prescripción, interrumpan el plazo desde su inicio.

Por otra se exige que exista una regularización administrativa para que la extensión de interrupción tenga lugar. Como destaca GÓMEZ TABOADA, «siendo obvio que la interrupción de la prescripción de la «principal» se producirá en el momento en que la Administración lleve a cabo cualquiera de las acciones previstas en el apartado 1. a) del artículo 68 LGT, no está tan claro que sea simultáneo el hito en el que haya de interpretarse interrumpida la prescripción de las "conexas», habida cuenta que la producción de ese efecto interruptivo se condiciona a que "en éstas se produzca o haya de producirse una tributación distinta", eventualidad que parece obvio no concurre desde el inicio de aquellas acciones, si no ya en un momento ulterior que será cuando, en su caso, se constate fehacientemente esa eventualidad» ${ }^{17}$.

Como paradigma podríamos suponer una empresa, por ejemplo, una sociedad papelera situada en Galicia es objeto de una inspec-

15 Eseverri Martínez, E. "La prescripción tributaria (nueva regulación)", en C. García- Herrera Blanco (cord.) IV encuentro de Derecho Financiero y Tributario (1 ${ }^{a}$ parte), en Documentos de Trabajo del IEF, núm. 13, 2016., La prescripción tributaria (nueva regulación), por ERNESTO ESEVERRI (Universidad de Granada). Págs. 69-77.

${ }_{16}$ Tejerizo López, J.M.: "La prescripción en materia tributaria, especial referencia a la eficacia de su interrupción respecto de las obligaciones conexas", UNED-AEDAF, 2016. Págs. 3-12.

17 Cordero González, Eva $\mathrm{M}^{\mathrm{a}}$ "La interrupción de la prescripción en relación con las obligaciones conexas tras la reforma de la Ley General Tributaria por Ley 34/2015". BIB 2016 2649. Págs. 1-27. 
ción en el año 2017, por parte de la Consejería de Hacienda, relativa al Impuesto sobre Emisiones de Óxido de Azufre, correspondiente al ejercicio 2014. La inspección termina en el año 2018 mediante una liquidación, que modifica la cuota tributaria a ingresar por dicho impuesto, incrementándola. Teniendo en cuenta que la cuota del Impuesto sobre Emisiones constituye un gasto deducible en el Impuesto sobre Sociedades (carácter estatal), expondremos las consecuencias de las actuaciones inspectoras de la Consejería de Hacienda autonómica y sus consecuencias respecto del plazo de prescripción del Impuesto sobre Sociedades correspondiente al ejercicio 2014. Los hechos que se presentan son los siguientes:

- En primer lugar, debemos destacar que según el artículo 66 de la $\mathrm{LGT}^{18}$, el procedimiento inspector se inicia dentro del plazo legalmente establecido de prescripción de los procedimientos administrativos, puesto que desde que se inicia el procedimiento inspector (año 2017) y el ejercicio comprobado (ejercicio 2014) han transcurrido tres años. No han transcurrido los cuatro años legalmente establecidos para que prescriba el derecho de la Administración.

- En segundo lugar, la LGT $^{19}$ establece que la prescripción de los derechos recogidos en el artículo 66 LGT, no afectará al derecho de la Administración para realizar comprobaciones e investigaciones conforme al artículo 115 de la Ley, es decir, que no prescribe ${ }^{20}$.

- En tercer lugar, se determina que, fruto del procedimiento inspector, se produce un incremento de la cuota tributaria, y por consiguiente un aumento de la cuota del Impuesto sobre emisiones, con lo cual, un aumento del gasto deducible en el Impuesto de Sociedades (IS en adelante).

- En cuarto lugar, debemos destacar que el incremento de la cuota tributaria del Impuesto sobre Emisiones está conectado con el IS, puesto que supone un gasto deducible del mismo,

18 Artículo 66 LGT. Plazos de prescripción. Prescribirán a los cuatro años los siguientes derechos: a) El derecho de la Administración para determinar la deuda tributaria mediante la oportuna liquidación.

19 Artículo 66 bis LGT. Derecho a comprobar e investigar. 1. La prescripción de derechos establecida en el artículo 66 de esta Ley no afectará al derecho de la Administración para realizar comprobaciones e investigaciones conforme al artículo 115 de esta Ley, salvo lo dispuesto en el apartado siguiente.

20 Cordero González, E.: "La interrupción de la prescripción en relación con las obligaciones conexas tras la reforma de la Ley General Tributaria por Ley 34/2015" en Civitas Revista Española de Derecho Financiero, núm. 170, 2016. Págs. 115-120. 
ello nos indicaría que nos encontramos con un supuesto de obligaciones conexas, reguladas en el artículo 68.9 de la $\mathrm{LGT}^{21}$. Además, según dicho precepto, es necesario que se produzca una tributación diferente como consecuencia de los criterios o elementos en los que se fundamente la regularización de la obligación con la que estén relacionadas las obligaciones tributarias conexas.

- En quinto lugar, el IS y el Impuesto sobre Emisiones de Óxido de Azufre son consideradas como obligaciones conexas, obligando a que, la liquidación del primero produzca su consideración como gasto en el segundo.

La cuestión a determinar es si ¿el hecho del inicio del procedimiento inspector sería presupuesto suficiente para que produjera la interrupción del plazo de prescripción del IS, de acuerdo con lo que establece el artículo 68.9 LGT? La respuesta a esta cuestión es, efectivamente, positiva. El inicio de las actuaciones inspectoras sobre el Impuesto sobre Emisiones de Óxido de Azufre, produce la interrupción del plazo de prescripción de cuatro años establecidos en el artículo 66, a) LGT, y, por lo tanto, también respecto del IS, por estar conectados.

Por lo tanto, en base a lo establecido anteriormente, las actuaciones inspectoras de la Consejería de Hacienda autonómica habrán interrumpido el plazo de prescripción del Impuesto sobre Sociedades correspondiente al ejercicio 2014 en las obligaciones conexas. El hecho de que se interrumpa el plazo de prescripción, respecto del Impuesto de Emisiones, también produce el mismo efecto (la interrupción del plazo de prescripción) sobre su obligación conexa, es decir sobre el IS.

21 Art 68.9 LGT. La interrupción del plazo de prescripción del derecho a que se refiere la letra a) del artículo 66 de esta Ley relativa a una obligación tributaria determinará, asimismo, la interrupción del plazo de prescripción de los derechos a que se refieren las letras a) y c) del citado artículo relativas a las obligaciones tributarias conexas del propio obligado tributario cuando en éstas se produzca o haya de producirse una tributación distinta como consecuencia de la aplicación, ya sea por la Administración Tributaria o por los obligados tributarios, de los criterios o elementos en los que se fundamente la regularización de la obligación con la que estén relacionadas las obligaciones tributarias conexas. 


\section{LAS OBLIGACIONES CONEXAS EN LOS PROCEDIMIENTOS DE COMPROBACIÓN}

Antes de analizar las obligaciones conexas en referencia a los procedimientos de Gestión, debemos especificar la definición de gestión tributaria, es definida ${ }^{22}$ a través de una serie de actuaciones que la Administración debe de llevar a cabo para la aplicación de los tributos (artículo 117 LGT) ${ }^{23}$, pero la LGT no la define como tal de forma explícita . La gestión tributaria engloba toda una serie de actuaciones que tienen por objeto la aplicación de los tributos, existiendo incluso una "cláusula de cierre" que definen como gestión tributaria todas aquéllas actuaciones que no encuadradas dentro de las funciones de inspección y recaudación.

ESEVERRI MARTÍNEZ aclara que, a la gestión tributaria se le encomienda como funciones ${ }^{24}$; Posibilitar el funcionamiento y normal aplicación de los tributos que integran el sistema; Controlar el cumplimiento de las obligaciones y deberes y la realización de las actuaciones atribuidas a los particulares, practicando las correccio-

22 Función administrativa dirigida a la aplicación de los tributos, que en un sentido amplio estaría integrada por todas las actividades tendentes a la cuantificación y determinación de la deuda tributaria (liquidación tributaria), la comprobación del comportamiento del sujeto pasivo por parte de la Administración (inspección) y la recaudación o pago de las deudas tributarias (recaudación), y que en un sentido estricto abarcaría únicamente la liquidación y comprobación.

23 Artículo 117 LGT. La gestión tributaria. 1. La gestión tributaria consiste en el ejercicio de las funciones administrativas dirigidas a: a) La recepción y tramitación de declaraciones, autoliquidaciones, comunicaciones de datos y demás documentos con trascendencia tributaria. b) La comprobación y realización de las devoluciones previstas en la normativa tributaria. c) El reconocimiento y comprobación de la procedencia de los beneficios fiscales de acuerdo con la normativa reguladora del correspondiente procedimiento. d) El control y los acuerdos de simplificación relativos a la obligación de facturar, en cuanto tengan trascendencia tributaria. e) La realización de actuaciones de control del cumplimiento de la obligación de presentar declaraciones tributarias y de otras obligaciones formales. f) La realización de actuaciones de verificación de datos. g) La realización de actuaciones de comprobación de valores. h) La realización de actuaciones de comprobación limitada. i) La práctica de liquidaciones tributarias derivadas de las actuaciones de verificación y comprobación realizadas. j) La emisión de certificados tributarios. k) La expedición y, en su caso, revocación del número de identificación fiscal, en los términos establecidos en la normativa específica. l) La elaboración y mantenimiento de los censos tributarios. m) La información y asistencia tributaria. n) La realización de las demás actuaciones de aplicación de los tributos no integradas en las funciones de inspección y recaudación. 2. Las actuaciones y el ejercicio de las funciones a las que se refiere el apartado anterior se realizarán de acuerdo con lo establecido en esta ley y en su normativa de desarrollo.

24 Martín Queralt, Juan; Lozano Serrano, Carmelo; Tejerizo López, José María; Casado Ollero, Gabriel" Curso de derecho financiero y tributario" Edición28 $8^{\mathrm{a}}$, lección 11 pág. 357. 
nes o regularizaciones (liquidaciones) que correspondan. Y como cláusula abierta negativa: realizar las demás actuaciones genéricas de aplicación de los tributos que no sean de inspección y recaudación ${ }^{25}$.

Los procedimientos de gestión, quedan afectos por la interrupción de la prescripción del derecho a liquidar y a devolver por parte de la Administración, respecto del derecho a liquidar otra obligación distinta, pero relacionada con ella (art. 68.9 LGT, obligaciones conexas). Lo que podía considerarse como un efecto expansivo de la interrupción de la prescripción del derecho a liquidar una obligación tributaria hacia otras diferentes con ella relacionadas, en razón a sus comunes elementos integradores ${ }^{26}$.

Para el desarrollo de las competencias de gestión, la LGT regula un total de cinco procedimientos, los cuales tiene un período de terminación determinado, que no es susceptible de ser ampliado, sin embargo sí que puede ser interrumpido de forma justificada. ${ }^{27}$

Los efectos que produce la regularización de las obligaciones tributarias conexas, serán visibles cuando la obligación principal haya sido objeto de algún procedimiento administrativo de revisión. Así pues, cuando la Administración haya dictado una liquidación tributaria a consecuencia de un procedimiento de regularización y, éste acto, haya sido impugnado en un procedimiento de revisión, si la resolución del recurso o reclamación, ha estimado total o parcialmente la pretensión del recurrente y existen obligaciones conexas con la que fue objeto de impugnación, en la fase de ejecución de dicha resolución, podrán ser objeto de regularización tributaria también las obligaciones conexas.

Los procedimientos de gestión tienen un plazo máximo de terminación de seis meses, tras el cual, se producirá generalmente la caducidad $^{28}$ de los mismos. Cumplido dicho plazo, sin haberse notifi-

25 Eseverri Martínez, E. "La prescripción tributaria (nueva regulación)", en C. García-Herrera Blanco (cord.) IV encuentro de Derecho Financiero y Tributario (1 ${ }^{a}$ parte), en Documentos de Trabajo del IEF, núm. 13, 2016: Consideraciones en torno al plazo de terminación de. los procedimientos de gestión tributaria, por ELENA MANZANO SILVA (Universidad de Extremadura). Págs. 127-136.

${ }^{26}$ Apartado 9 incorporado al artículo 68 LGT, número diez, del artículo Único, de la Ley 34/2015.

27 Eseverri Martínez, E. "La prescripción tributaria (nueva regulación)", en C. García-Herrera Blanco (cord.) IV encuentro de Derecho Financiero y Tributario (1 ${ }^{a}$ parte), en Documentos de Trabajo del IEF, núm. 13, 2016. Consideraciones en torno al plazo de terminación de los procedimientos de gestión tributaria, por ELENA MANZANO SILVA (Universidad de Extremadura). Págs. 127-136.

${ }^{28}$ Prescripción: Concepto jurídico en virtud del cual el transcurso de tiempo consolida situaciones de hecho. Permite la extinción de derechos (extintiva) o ad- 
cado la correspondiente resolución de liquidación al administrado, la Administración Tributaria deberá iniciar un nuevo procedimiento (el anterior habrá caducado), siempre que no haya transcurrido el plazo de prescripción. Con ello se pretende aclarar que no se produce, por sí sola, la prescripción de los derechos de la Administración Tributaria, solo la caducidad de las actuaciones realizadas.

Así, el art. 66 bis LGT diferencia la prescripción del derecho a liquidar, de la prescripción del derecho a comprobar. El derecho a comprobar no prescribe (a diferencia del derecho a liquidar) estableciendo a continuación, el precepto más arriba señalado, una regla especial para las bases imponibles negativas o cuotas compensadas o pendientes de compensación o de deducciones aplicadas o pendientes de aplicación(...). Implantándose una nueva prescripción de diez años para comprobar las bases o cuotas pendientes de compensar, computados desde la finalización del plazo reglamentario para la presentación de la autoliquidación en que se generó el derecho. De esta manera se incorpora a la LGT y generaliza lo dispuesto en el art. 26.5 de la LIS 27/201429.

Por otro lado, CORDERO GONZÁLEZ reconoce que en el art. 115 LGT, "la Administración puede comprobar y recalificar jurídicamente los negocios jurídicos celebrados en ejercicios prescritos, cuyas consecuencias desplieguen efectos en ejercicios no prescritos.

$\mathrm{Al}$ analizar las obligaciones tributarias conexas dentro del procedimiento de inspección, es ineludible destacar en primer lugar al artículo $141 \mathrm{LGT}^{30}$, definiendo la inspección tributaria como un con-

quisición de cosas ajenas (liberatoria - usucapión). Caducidad: Extinción de un derecho por el transcurso del tiempo conferido para su ejercicio.

29 Artículo 26 Ley 27/2014 de 27 de noviembre, del Impuesto sobre Sociedades. Compensación de bases imponibles negativas. 5. El derecho de la Administración para iniciar el procedimiento de comprobación de las bases imponibles negativas compensadas o pendientes de compensación prescribirá a los 10 años a contar desde el día siguiente a aquel en que finalice el plazo establecido para presentar la declaración o autoliquidación correspondiente al período impositivo en que se generó el derecho a su compensación. Transcurrido dicho plazo, el contribuyente deberá acreditar las bases imponibles negativas cuya compensación pretenda mediante la exhibición de la liquidación o autoliquidación y la contabilidad, con acreditación de su depósito durante el citado plazo en el Registro Mercantil.

30 Artículo 141 LGT. La inspección tributaria. La inspección tributaria consiste en el ejercicio de las funciones administrativas dirigidas a: a) La investigación de los supuestos de hecho de las obligaciones tributarias para el descubrimiento de los que sean ignorados por la Administración. b) La comprobación de la veracidad y exactitud de las declaraciones presentadas por los obligados tributarios. c) La realización de actuaciones de obtención de información relacionadas con la aplicación de los tributos, de acuerdo con lo establecido en los artículos 93 y 94 de esta ley. d) La comprobación del valor de derechos, rentas, productos, bienes, patrimonios, em-

(C) UNED. Revista de Derecho UNED, núm. 27, 2021 
junto de funciones administrativas, que no deben identificarse única y exclusivamente con funciones de investigación, sino que además se añaden otro tipo de funciones: actuaciones de comprobación e investigación y actuaciones de obtención de información en los términos establecidos en los artículos 93 y 94 LGT (GARCÍA DÍEZ) ${ }^{31}$.

MARTÍN QUERALT determina que el artículo 141 LGT permite efectuar una sistematización de las funciones administrativas de la inspección tributaria ${ }^{32}$ : Funciones contraloras que pueden llevar a actuaciones de comprobación inquisitiva y limitada; Comprobadoras; Funciones de investigación de presupuestos de hechos; Funciones de obtención de información relacionadas con la aplicación de los tributos; Funciones de liquidación; Funciones información a obligados tributarios sobre derechos /obligaciones; Funciones de intervenciones tributarias y Demás funciones que establezcan las disposiciones o autoridades.

El procedimiento de inspección, como cualquier procedimiento administrativo, tiene como finalidad, además de encauzar las actuaciones y los actos administrativos que en su seno se realicen o dicten, garantizar los derechos de los ciudadanos afectados por el mismo. En este sentido, el hecho que el procedimiento inspector cumpla los plazos legalmente establecidos para su desarrollo y terminación, no constituye sino una garantía más del interesado, dotando de seguridad jurídica la relación entre Administración y obligado tributario.

presas y demás elementos, cuando sea necesaria para la determinación de las obligaciones tributarias, siendo de aplicación lo dispuesto en los artículos 134 y 135 de esta ley. e) La comprobación del cumplimiento de los requisitos exigidos para la obtención de beneficios o incentivos fiscales y devoluciones tributarias, así como para la aplicación de regímenes tributarios especiales. f) La información a los obligados tributarios con motivo de las actuaciones inspectoras sobre sus derechos y obligaciones tributarias y la forma en que deben cumplir estas últimas. g) La práctica de las liquidaciones tributarias resultantes de sus actuaciones de comprobación e investigación. h) La realización de actuaciones de comprobación limitada, conforme a lo establecido en los artículos 136 a 140 de esta ley. i) El asesoramiento e informe a órganos de la Administración pública. j) La realización de las intervenciones tributarias de carácter permanente o no permanente, que se regirán por lo dispuesto en su normativa específica y, en defecto de regulación expresa, por las normas de este capítulo con exclusión del artículo 149. k) Las demás que se establezcan en otras disposiciones o se le encomienden por las autoridades competentes.

31 García Díez, Claudio; Mallada Fernández, Covadonga; Sánchez Pedroche, José Andrés. "Derecho tributario. Procedimientos tributarios". $2^{\text {a }}$ Edición, UDIMA (Universidad a Distancia de Madrid) Ediciones CEF. -2016 Pág.360 y siguientes.

32 Martín Queralt, Juan; Lozano Serrano, Carmelo; Tejerizo López, José María; Casado Ollero, Gabriel" curso de derecho financiero y tributario" Edición 28a , lección 13 pág. 450 y siguientes. 
Estamos ante una materia que ha devenido especialmente litigiosa. La propia Exposición de Motivos de la LGT señala que "Constatada la existencia de numerosas incidencias en la interpretación de la regulación de los plazos de las actuaciones inspectoras, se hace precisa una nueva regulación que, sin menoscabar los derechos y garantías de los obligados tributarios, permita reducir la conflictividad en esta materia.". Con esto, en primer lugar, asevera ESEVERRI MARTÍNEZ, que" a través de la nueva regulación introducida sobre los plazos del procedimiento inspector, se pretende simplificar de manera importante la normativa vigente, al eliminarse un amplio y complejo sistema de supuestos de interrupciones justificadas, dilaciones no imputables a la Administración, y de ampliación del plazo, suprimiéndose el supuesto de interrupción injustificada durante más de seis meses". En segundo término, continúa explicando ESEVERRI MARTÍNEZ, "se persigue otorgar una mayor seguridad jurídica en cuanto al cómputo de los plazos del procedimiento inspector, incorporando nuevas obligaciones para informar al obligado tributario de las vicisitudes de dicho plazo (duración y, en su caso, suspensión y extensión del mismo), de forma que el obligado pueda conocer claramente cuál es la fecha límite del procedimiento”. Por último, el autor especifica que "se busca reducir significativamente la conflictividad tributaria33". ESEVERRI MARTÍNEZ termina concluyendo "se pretende que el obligado tributario conozca la fecha de finalización más probable del procedimiento inspector, lo cual contribuye a la defensa de sus intereses".

La reforma de la LGT implica un incremento del plazo del procedimiento de inspección. Así, las actuaciones del procedimiento de inspección deberán concluir, como indica el remozado artículo 150 LGT, con carácter general, en el plazo de 18 meses, que se incrementará hasta los 27 meses cuando, en cualquiera de las obligaciones tributarias o periodos objeto de comprobación resulte que, bien el volumen de operaciones del obligado tributario sea igual o superior al requerido para auditar cuentas, o bien el obligado tributario esté integrado en un grupo sometido al régimen de consolidación fiscal o al régimen especial de grupo de entidades que esté siendo objeto de comprobación inspectora. Sin embargo, los efectos que pueden producir la superación del plazo del procedimiento inspector no varían

33 Eseverri Martínez, E. "La prescripción tributaria (nueva regulación)", en C. García-Herrera Blanco (cord.) IV encuentro de Derecho Financiero y Tributario $\left(1^{a}\right.$ parte), en Documentos de Trabajo del IEF, núm. 13, 2016. El plazo de duración de las actuaciones inspectoras tras la reforma de la Ley General Tributaria introducida por la Ley 34/2015, de 21 de septiembre, por JUAN CALVO VÉRGEZ (Universidad de Extremadura). Págs. 127-136. 
respecto a las actualmente previstas, es decir, no se producirá la interrupción de la prescripción por el simple transcurso del plazo de dicho procedimiento. Lo que realmente supone el artículo 68.9 LGT es la interrupción del plazo de algunos derechos de la Hacienda Pública (como puede ser liquidar el tributo).

La interrupción de la prescripción afecta a las obligaciones conexas del mismo obligado, cuando se ha obtenido una nueva calificación. La interrupción de la prescripción afectará a la exigencia de la deuda o al reconocimiento de una devolución en los tributos del mismo obligado, cuando estén conexos con el tributo alterado, aunque deban considerarse prescritos por aplicación de las reglas generales del instituto que se tenga en consideración. El inicio de actuaciones tributarias de inspección, interrumpe al plazo de prescripción de las obligaciones conexas, hasta que aquellas finalicen. Cuando la Administración tributaria regulariza una obligación tributaria relacionada con otra del mismo obligado, y la Administración (de oficio o en virtud de una solución de rectificación de autoliquidación presentada por el obligado tributario) pretenda modificar dicha obligación conexa (aplicando criterios en los que se ha fundamentado la regularización de la primera obligación), se producirá , en base al artículo 68.9 LGT ,la interrupción del plazo de la prescripción, para evitar situaciones en las que los obligados tributarios y el acreedor puedan resultar gravemente perjudicados, por la circunstancia de que la deuda se encontrase ya prescrita al momento de su regularización.

No podemos dejar de destacar el régimen transitorio en la LGT, formado por el conjunto de disposiciones de la Ley 34/2015 reguladoras de aquellas situaciones que, si bien existen con anterioridad a la reforma, resulta necesaria su contemplación hasta que se produjera la definitiva entrada en vigor de la Ley citada. Con el transcurrir del tiempo, la normativa (ley anterior a la reforma parcial de la LGT) deja de ser suficiente para regular situaciones que estaban previstas inicialmente siendo adecuadas temporal y normativamente, devienen insuficientes y surge la necesidad de modificarlas o incluso sustituirlas con la finalidad de adoptarlas a las nuevas realidades sociales. Como consecuencia de la situación descrita pueden surtir colisiones entre la Ley "nueva" y Ley "antigua" reguladoras de una misma situación. La solución al conflicto normativo es acudir a su regulación a través del régimen transitorio, produciéndose una adaptación entre los preceptos de la nueva ley a los estados nacidos al amparo de la ley anterior. 
El régimen transitorio ${ }^{34}$ de la Ley 34/2015 pretende dar solución a los efectos de las modificaciones producidas con el devenir del transcurso del tiempo y la religiosidad en los ejercicios futuros que pueda surgir entre normas, cuestión que distaría de ser pacífica.

La Ley 34/2015 en su Disposición final duodécima, especifica cuándo se produce la entrada en vigor de la misma, al establecer que:" esta ley entrará en vigor a los veinte días de su publicación en el Boletín Oficial del Estado" (i.e. el 12 de octubre de 2015), sin embargo, la propia Disposición determina las normas específicas de entrada en vigor, relativas a:

- Artículos 29 y 200 de la Ley 58/2003.

Las modificaciones introducidas en dichos artículos, relativas a la infracción por incumplir obligaciones contables y registrales, entraron en vigor el 1 de enero de 2017, y

- Algunas de las modificaciones relativas a la Ley Orgánica 12/1995, de 12 de diciembre, de Represión del Contrabando, entraron en vigor a los tres meses de la publicación en el BOE de la Ley 34/2015.

No obstante, se establece un régimen transitorio en algunas materias, ente las que debemos destacar que el régimen de la interrupción de la prescripción para las obligaciones conexas de titularidad del mismo obligado, se aplicará a aquellos casos en los que la interrupción se producirá una vez entrada en vigor la Ley 34/2015. En consecuencia, la interrupción de la prescripción de un tributo supondrá la interrupción de los plazos de prescripción de otras obligaciones tributarias conexas cuya titularidad correspondan al mismo obligado tributario.

Cuando la Ley 34/2015 introduce el apartado 9 en el artículo 68, referente a la interrupción del plazo de prescripción relativa a las obligaciones conexas, viene a decirnos que dicha interrupción operará cuando existan obligaciones conexas, aun cuando sean posteriores a la regularizada, generándose una tributación distinta de aquellos criterios en los que se basa la regularización. De ahí que la propia Disposición transitoria única, referente al Régimen transitorio, en su apartado 3 establezca:" La nueva redacción del apartado 9 del artículo 68 de la Ley 58/2003, de 17 de diciembre, General Tributa-

34 Para 2015 se reguló un régimen transitorio, siendo la fecha de referencia para determinar la concurrencia de los requisitos necesarios para la inclusión en el primer listado el 31 de julio de 2015. Este primer listado se publicó en el último trimestre de 2015. 
ria, será aplicable a aquellos casos en los que la interrupción del plazo de prescripción del derecho al que se refiere el párrafo a) del artículo 66 de la Ley 58/2003, de 17 de diciembre, General Tributaria, se produzca a partir de la fecha de entrada en vigor de esta Ley".

\section{OBLIGACIONES CONEXAS EN EL RECURSO DE REPOSICIÓN}

\section{VI.A. Concepto, objeto y naturaleza ${ }^{35}$.}

Cabe destacar el carácter potestativo del recurso de reposición en el que se podrán reclamar "los actos de la administración Tributaria susceptibles de reclamación económico-administrativa" 36 Por tanto, para la interposición del recurso de reposición es necesaria la existencia de un acto de gestión que declare derechos u obligaciones a cargo de la Hacienda Pública que afecte, individualmente a personas determinadas. Corolario de ello es que, la materia reclamable se refiere a situaciones jurídicas individualizadas.

La doctrina (GARCÍA DÍEZ, CLAUDIO; MALLADA FERNÁNDEZ, COVADONGA; SÁNCHEZ PEDROCHE, JOSÉ ANDRÉS) destaca como características del recurso de reposición ${ }^{37}$ : Carácter previo a la reclamación económico-administrativa; Carácter potestativo; Si se interpone, no podrá interponerse reclamación económico-administrativa en tanto no exista resolución de recurso de reposición; Si en el plazo de la interposición del recurso se presentase recurso de reposición y reclamación económico-administrativa, se tramitará el pre-

35 Martín Queralt, Juan; Lozano Serrano, Carmelo; Tejerizo López, José María; Casado Ollero, Gabriel" curso de derecho financiero y tributario" Edición28 ${ }^{\mathrm{a}}$, lección 17. Pág.709 y siguientes

36 Artículo 222 LGT. Objeto y naturaleza del recurso de reposición.1. Los actos dictados por la Administración tributaria susceptibles de reclamación económico-administrativa podrán ser objeto de recurso potestativo de reposición, con arreglo a lo dispuesto en este capítulo.2. El recurso de reposición deberá interponerse, en su caso, con carácter previo a la reclamación económico-administrativa. Si el interesado interpusiera el recurso de reposición no podrá promover la reclamación económico-administrativa hasta que el recurso se haya resuelto de forma expresa o hasta que pueda considerarlo desestimado por silencio administrativo. Cuando en el plazo establecido para recurrir se hubieran interpuesto recurso de reposición y reclamación económico-administrativa que tuvieran como objeto el mismo acto, se tramitará el presentado en primer lugar y se declarará inadmisible el segundo.

37 García Díez, Claudio; Mallada Fernández, Covadonga; Sánchez Pedroche, José Andrés. "Derecho tributario. Procedimientos tributarios". $2^{\mathrm{a}}$ Edición, UDIMA (Universidad a Distancia de Madrid) Ediciones CEF. -2016 Pág.544 y siguientes. 
sentado en primer lugar y se declarará inadmisible el segundo; Se interpone en un mes desde notificación del acto que se recurre; Conoce y resuelve el recurso el mismo acto que dictó el acto recurrido; Plazo máximo para resolver es de un mes desde su presentación.

Dentro de las novedades derivadas de la regulación legal nos referiremos a la introducción del apartado 5 en el artículo 224 LGT y apartado 3 del artículo 225 LGT:

Introducción del apartado 5 en el artículo 224 LGT, en relación con las obligaciones conexas ${ }^{38}$ : "En los casos del artículo 68.9 de esta Ley, si el recurso afecta a una deuda tributaria que, a su vez, ha determinado el reconocimiento de una devolución a favor del obligado tributario, las garantías aportadas para obtener la suspensión garantizarán asimismo las cantidades que, en su caso, deban reintegrarse como consecuencia de la estimación total o parcial del recurso".

En relación con este apartado CREMADES SCHULZ advierte que en los casos del artículo 68.9 LGT, al interponerse recurso que afecte a una deuda tributaria y, a su vez, se haya determinado el reconocimiento de una devolución a favor del obligado tributario, las garantías aportadas para obtener la suspensión, deben garantizar asimismo las cantidades que, en su caso, resulten a reintegrar como consecuencia de la estimación total o parcial del recurso. La interposición del recurso de reposición por el administrado, interrumpe el plazo de prescripción, y volverá a interrumpirse a causa de los trámites y actuaciones del propio procedimiento revisor, siempre que el interesado hubiera tenido conocimiento formal del mismo.

Para algunos autores (MARTÍN QUERALT, JUAN; LOZANO SERRANO, CARMELO; TEJERIZO LÓPEZ, JOSÉ MARÍA; CASADO OLLERO, GABRIEL) "en los recursos administrativos se produce la prescripción de las actuaciones, cuando transcurra cuatro años desde la última actuación interruptiva, y sin que la resolución desestimatoria (por silencio administrativo negativo), sirva para interrumpir dicho cómputo, al no ser una resolución propiamente dicha, sino una fictio iuris, a la que el interesado puede acogerse a efectos de proseguir su impugnación. El efecto interruptivo de la interposición del recurso, y de su normal tramitación, no admite excepciones, y si el acto recurrido se declarado nulo de pleno derecho, la interposición del recurso no produce la interrupción de la

38 Cremades Schulz, M.: "Las obligaciones conexas antes de la Reforma de la Ley General Tributaria por la Ley 34/2015”, en Actualidad Jurídica Uría-Menéndez, núm. 42, 2016. Págs. 3-12. 
prescripción" ${ }^{39}$. En definitiva, lo que estos autores nos vienen a aclarar es que, cuando exista una regularización administrativa que (en el supuesto en el que se hubiera cuestionado algún extremo de lo autoliquidado por un contribuyente), suponga que se le reconozca el derecho a percibir una devolución al administrado, se puede recurrir el acto administrativo y, por ende, suspender su ejecución. Pero no por ello se evitará que se ejecute la devolución a favor del interesado (previsión legal que viene a avalar, ya expresamente, que la suspensión no decae la presunción de legalidad del acto ${ }^{40}$ ), sin embardo, será necesario que se exija al contribuyente que preste una caución con la finalidad de garantizar al erario público su recuperación por lo indebidamente devuelto, en el caso "de la estimación total o parcial del recurso interpuesto por el contribuyente". Se garantiza, con ello, el reintegro de las devoluciones que estén vinculadas a liquidaciones que son objeto de recurso por el mismo obligado.

Introducción del apartado 3 del artículo 225 LGT $^{41}$. CREMADES SCHULZ afirma que "las novedades normativas tributarias producen efectos en relación con el apartado 3 del artículo 225 LGT $^{42}$ : el recurso de reposición (previamente presentado), podría no ser resuelto en plazo, sin que ello fuere necesario para considerar que existe silencio administrativo negativo, puesto que el plazo para resolverlo podría ampliarse hasta dos meses más, en base al artículo anteriormente citado". De esta forma, continúa afirmando CREMADES SCHULZ, "suceder que el tribunal no deba declarar la inadmisibilidad de la reclamación, por haberse interpuesto en el plazo de un mes desde que se interpuso el recurso de reposición, sin em-

39 Martín Queralt, Juan; Lozano Serrano, Carmelo; Tejerizo López, José María; Casado Ollero, Gabriel" Curso de derecho financiero y tributario" Edición 28 $8^{\text {. }}$ Lección 17. Pág. 713.

40 Es más, de ser acertada esa lectura "alternativa” del nuevo 68.9 LGT, el Parlamento no habría tenido motivos para negarse a incorporar la enmienda que (como luego se expondrá), propuesta por CiU, pretendía que la suspensión evitara que el contribuyente se viera compelido a liquidar los ejercicios posteriores según el criterio seguido por la AEAT con motivo de la regularización de la "conexa" primitiva.

41 Artículo 225.3 LGT: "En ejecución de una resolución que estime total o parcialmente el recurso contra la liquidación de una obligación tributaria conexa a otra del mismo obligado tributario de acuerdo con el artículo 68.9 de esta Ley, se regularizará la obligación conexa distinta de la recurrida en la que la Administración hubiese aplicado los criterios o elementos en que se fundamentó la liquidación de la obligación tributaria objeto de la reclamación.

Si de dicha regularización resultase la anulación de la liquidación de la obligación conexa distinta de la recurrida y la práctica de una nueva liquidación que se ajuste a lo resuelto en el recurso, será de aplicación lo dispuesto en el artículo 26.5 de esta Ley".

42 Cremades Schulz, M.: "Las obligaciones conexas antes de la Reforma de la Ley General Tributaria por la Ley 34/2015", en Actualidad Jurídica Uría-Menéndez, núm. 42, 2016. Págs. 3-12. 
bargo, al reclamar el expediente administrativo al órgano administrativo, se podría manifestar que, el plazo para resolver el recurso de reposición todavía no ha concluido, por haberse ampliado por eso no procede remitirlo".

Con la entrada de dicho apartado, el plazo se computará desde el día siguiente a la presentación del recurso, hasta la notificación de la resolución expresa o que haya transcurrido el plazo máximo para resolver.

Los artículos 225.3 y 239.7 de la LGT señalan : «en ejecución ${ }^{43}$ de una resolución que estime total o parcialmente» el recurso o reclamación «contra la liquidación de una obligación tributaria conexa a otra del mismo obligado tributario de acuerdo con el artículo 68.9 de esta Ley, se regularizará la obligación conexa distinta de la recurrida en la que la Administración hubiese aplicado los criterios o elementos en que se fundamentó la liquidación de la obligación tributaria objeto de la reclamación» ${ }^{44}$.

Por su parte CORDERO GONZÁLEZ estipula que "la extensión de efectos a las obligaciones tributarias conexas, tendrá lugar en sede de ejecución de la resolución que estimó total o parcialmente el recurso, contra la liquidación impugnada”. Así pues, continúa diciendo," la ejecución de la resolución que confirme la tributación inicialmente declarada, no sólo determinará la anulación de la liquidación al alza del primer periodo, sino también la emisión de una liquidación a ingresar en relación con los posteriores, respecto de los que se hubiera reconocido la devolución". Otro de los aspectos conflictivos que CORDERO GONZÁLEZ encuentra en la nueva regulación, será la exigencia de intereses de demora por la liquidación dictada en ejecución de la resolución estimatoria: "Esta norma, parece querer amparar, que los intereses se exijan desde el fin del plazo para autoliquidar hasta el momento en que se dicte la nueva liquidación, a pesar de haberse declarado correctamente". Esta tesis, por el contrario, resulta contradictoria con la doctrina

43 Por "actuaciones de ejecución" nos referimos al supuesto de dictar una liquidación en ejecución de una resolución anulatoria de una previa liquidación sin reponer las actuaciones del procedimiento de liquidación. Ello sin desconocer que el diferente supuesto de retroacción de actuaciones también implica, genéricamente, una actividad de ejecución de la resolución anulatoria antecedente.

${ }^{44}$ Memoria del Análisis del Impacto Normativo "Si el interesado interpone recurso de reposición o reclamación económico-administrativa contra la regularización practicada, la resolución total o parcialmente estimatoria que se dicte tendrá eficacia no solo respecto de la liquidación recurrida, sino también respecto de la liquidación administrativa de la obligación tributaria conexa, debiendo dictarse una liquidación de ésta última en el sentido derivado de la resolución» Págs. 2 y siguientes. 
del TS, que ha rechazado que los intereses se devenguen hasta la fecha de la emisión de la nueva liquidación, cuando no exista demora imputable al obligado tributario. "La exigencia de intereses podría empeorar la limitación de la reformatio in peius, pues el recurso presentado frente a la primera liquidación podría perjudicar la situación del recurrente, si los intereses que se le exigen por la liquidación de la conexa, superen los que se le habían girado por la regularización inicial" 45 . Con todo lo expuesto, CORDERO GONZÁLEZ concluye que "lo que se pretende en proceder a unificar los procedimientos referentes al recurso de reposición y reclamaciones económico-administrativas bajo una misma regulación respecto de la ejecución". Como anteriormente se ha comentado, ultima, "se procederá a la anulación de la liquidación de la obligación tributaria conexa y se dictará una liquidación con el mismo régimen de intereses de demora, aplicable a la liquidación impugnada y anulada, entendiéndose, aplicable a las liquidaciones provisionales, dictadas en amparo del artículo 101.4 LGT por estar pendiente de comprobación definitiva o liquidación no firme."

\section{OBLIGACIONES CONEXAS EN LAS RECLAMACIONES ECONOMICO-ADMINISTRATIVAS}

Para la doctrina (MARTÍN QUERALT, JUAN; LOZANO SERRANO, CARMELO; TEJERIZO LÓPEZ, JOSÉ MARÍA; CASADO OLLERO, GABRIEL) las reclamaciones económico-administrativas, son una clase de recurso administrativo cuya finalidad es examinar la legalidad de los actos administrativos de contenido económico, regulados por el Derecho financiero y funciona como un presupuesto necesario del recurso ante la jurisdicción contencioso-administrativa regulados por el Derecho Administrativo ${ }^{46}$.

Cuando se interpone una reclamación económico-administrativa sobre una liquidación tributaria efectuada por la Administración Tributaria, las resoluciones que adopten los órganos de revisión económico-administrativos, puede ser: estimatorias, desestimatorias o de inadmisibilidad. Por ende, cabe la posibilidad que la re-

45 Cordero González, Eva $\mathrm{M}^{\mathrm{a}}$. "La interrupción de la prescripción en relación con las obligaciones conexas tras la reforma de la Ley General Tributaria por Ley 34/2015". Revista española de Derecho Financiero num.170/2016 parte Estudios Editorial Civitas, SA, Pamplona. 2016. BIB 2016 2649. Págs. 1-27.

46 Martín Queralt, Juan; Lozano Serrano, Carmelo; Tejerizo López, José María; Casado Ollero, Gabriel" curso de derecho financiero y tributario" Edición28 $8^{\mathrm{a}}$, lección 17. pág.713 y siguientes. 
solución estimatoria anule total o parcialmente el acto impugnado por razones de Derecho Sustantivo o por defectos formales (art. 239 de la LGT). Es decir, tanto la anulación por motivos formales, como por motivos materiales de liquidaciones tributarias, son causas por las que, los órganos económico-administrativos, pueden resolver los expedientes planteados ante ellos, sin olvidar, los supuestos tasados de declaración de nulidad de pleno derecho (art. 217 de la LGT) que han permanecido inalterados, pese a las modificaciones introducidas por la entrada en vigor de la Ley 34/2015, de 21 de septiembre(ESEVERRI MARTÍNEZ) ${ }^{47}$.

Las reclamaciones económico-administrativas gozan de una especialidad, las funciones de la Administración tributaria se ejercerán con la separación de dos órdenes: la aplicación de los tributos y la resolución de las reclamaciones (contra dicha aplicación que se interpone). Ambas funciones serán encomendadas a órganos diferentes (separación de poderes en lo económico-administrativo).

Como novedades derivadas de la regulación legal, se encuentra la introducción del apartado 7 del artículo 239 LGT el cual establece "en ejecución de una resolución que estime total o parcialmente la reclamación contra la liquidación de una obligación tributaria conexa a otra del mismo obligado tributario de acuerdo con el artículo 68.9 de esta ley, se regularizará la obligación conexa distinta de la recurrida que la Administración hubiese dictado en aplicación de los criterios o elementos en que se fundamentó la liquidación de la obligación tributaria objeto de la reclamación". Si de dicha regularización, resultase la anulación de la liquidación de la obligación conexa distinta de la recurrida, y se practica una nueva liquidación administrativa que se ajuste a lo resuelto por el Tribunal, será de aplicación lo dispuesto en el artículo 26.5 de esta Ley. Así pues, la ejecución de la resolución que confirme la tributación inicialmente declarada, no sólo determinará la anulación de la liquidación al alza del primer periodo, sino también la emisión de una liquidación a ingresar, en relación con los posteriores, respecto de los que se hubiera reconocido la devolución.

Como efectos, podríamos destacar que, si el interesado interpone recurso de reposición o una reclamación económico-administrativa contra la regularización practicada, la resolución que se dicte (total o parcialmente estimatoria) tendrá eficacia directa, no solo respecto

47 Eseverri Martínez, E. “La prescripción tributaria (nueva regulación)”, en C. García-Herrera Blanco (cord.) IV encuentro de Derecho Financiero y Tributario (1 ${ }^{a}$ parte), en Documentos de Trabajo del IEF, núm. 13, 2016. Retroacción de actuaciones y actuaciones de ejecución, por ENRIQUE DE MIGUEL CANUTO (Universitat de Valencia).Págs. 45-57.

(C) UNED. Revista de Derecho UNED, núm. 27, 2021 
de la liquidación recurrida, sino también, respecto de la liquidación administrativa de la obligación conexa, debiendo dictarse una liquidación de ésta última, en el sentido derivado de la resolución.

La aplicación de los artículos 225.3 y 239.7 de la LGT ha de excluirse cuando la estimación de la reclamación administrativa, venga motivada por causas que no sean (como señala la Memoria de Análisis del Impacto Normativo ${ }^{48}$ ), "una correcta tributación global, inicialmente propuesta por el obligado. De manera que la estimación de la reclamación, frente a la primera liquidación, suponga su confirmación implícita y determine el contenido de la segunda liquidación”. En este sentido, la enmienda núm. 106 al Proyecto de Ley, exigía incorporar a estos preceptos un inciso final para que la liquidación, que se emitiera vía ejecución, tuviera en cuenta los términos que hubieran sido concretados en la liquidación inicial anulada, con la finalidad de evitar la discrecionalidad administrativa y la extensión de la liquidación a aspectos no inicialmente contemplados. Algunos autores ${ }^{49}$ destacan que en el control que se lleve a cabo de la ejecución realizada, será fundamental tener en cuenta que los propios artículos 225.3 y 239.7 LGT señalan que la nueva liquidación, ha de ajustarse a lo resuelto en el recurso. Si, como consecuencia de la aplicación del mandato de los artículos citados, hubiere que compensar cantidades a ingresar y a devolver, el artículo 73.1 LGT, modificado por la Ley 34/2015, prevé que la Administración Tributaria, de oficio y en plazo de ingreso en período voluntario, podrá proceder a esa compensación evitando que se produzcan devoluciones tributarias, cuando exista una obligación de pago derivada de otra conexa.(ESEVERRI MARTÍNEZ)50. El derecho a practicar posibles liquidaciones, no prescribe, mientras no se resuelvan los recur-

48 El 27 de octubre de 2017 el Consejo de Ministros aprobó el Real Decreto 931/2017 por el que se regula la Memoria del Análisis de Impacto Normativo y que deroga el anterior texto del año 2009. El nuevo Real Decreto tiene por objeto desarrollar las previsiones contenidas en la nueva redacción dada al artículo 26.3 de la Ley 50/1997, de 27 de noviembre, del Gobierno por Ley 40/2015, de 1 de octubre, de Régimen Jurídico del Sector Público, en lo que se refiere a la memoria del análisis de impacto normativo que debe acompañar a los anteproyectos de ley y proyectos de reales decretos-leyes, reales decretos legislativos y normas reglamentarias. Se adapta de esta forma a las novedades de las nuevas leyes administrativas y a las recomendaciones y mejores prácticas de la OCDE y de la Unión Europea. Asimismo, el texto recoge un mandato de 6 meses para la adaptación de la actual Guía Metodológica para la elaboración de la MAIN. Pág 2 y ss.

49 AA.VV.: "La interrupción de la prescripción en relación con las obligaciones conexas tras la reforma de la Ley General Tributaria por Ley 34/2015", en Boletín Jurídico Gestión Tributaria Territorial, 22 de julio de 2016. Pág.1-27.

50 Eseverri Martínez, E. "La prescripción tributaria (nueva regulación)”, en C. García-Herrera Blanco (cord.) IV encuentro de Derecho Financiero y Tributario (1 ${ }^{a}$ parte), 
sos o reclamaciones interpuestos. Lo relevante de esta nueva redacción es que el Legislador viene a avalar la pretendida ortodoxia de la actuación de la Administración, al haber dictado un acto distinto (y, también, cabe asumir ulterior) al recurrido "en aplicación de los criterios o elementos en que se fundamentó" la impugnada, y ello sin especificar (pues aquí, y en todo lo que atañe a las "conexas", es lo relevante) que ese escenario solo resultaría factible de no mediar suspensión alguna sobre el acto recurrido.

Ergo es obvio que, también en este escenario, el legislador da por sentado que esa actuación posterior, debió tomar como base los postulados del acto anterior (cuestionado por el contribuyente y aun cuando aquél estuviera suspendido), asunción que solo cabe si la presunción de legalidad, no se ve afectada en modo alguno por la suspensión.

“El asunto es grave”, afirma (JAVIER GÓMEZ TABOADA) 51 ,pues "entraña una pérdida sustancial de la capacidad de obrar de los contribuyentes (i.e.: de su libertad), que se ve sensiblemente mermada por la victoriosa omnipotencia del Leviatán que, así, degrada a los contribuyentes de su condición de ciudadanos a la de súbditos ".

\section{CONCLUSIONES}

Se tenían muchas esperanzas con la aprobación de la reforma parcial de la LGT a través de la Ley 34/2015. Se apelaba a la reforma para poder aclarar todas aquellas cuestiones que resultaban dudosas y ambiguas, planteadas no solo por la doctrina sino también por la ciudadanía. Se comprobaba que, ante las exorbitantes potestades de la Administración, los administrados no podía sino acatar sus resoluciones administrativas, en detrimento de los intereses generales, cuando de obligaciones "vinculadas" se trataban. Al pretender reclamar los administrados, se podían encontrar con la "sorpresa" que hubiera prescrito.

Cuando la ley 34/2015 introduce el apartado 9 del art 68 de la LGT, parecía abrirse una nueva expectativa que venía a esclarecer tanto conceptos indeterminados, como situaciones injustas, en ocasiones para el administrado, en ocasiones (en menor medida) para la

en Documentos de Trabajo del IEF, núm. 13, 2016. La prescripción tributaria (nueva regulación), por ERNESTO ESEVERRI (Universidad de Granada). Pág. 69-77.

51 Gómez Taboada, Javier" El envés de las obligaciones conexas ¿victoria del orden o derrota de la justicia?" Documentos - Instituto de Estudios Fiscales, ISSN 1578-0244, Nº 19, 2015, págs. 50-60.

(C) UNED. Revista de Derecho UNED, núm. 27, 2021 
Administración Tributaria, como consecuencia de la tramitación de diversos procedimientos tributarios, recursos y reclamaciones económico-administrativas, en concordancia con el instituto de la prescripción.

Durante un período de tiempo indeterminado se resolvieron y esclarecieron todas aquellas vicisitudes que surgieron acerca de la "relación", "vinculación "o "conexión" entre obligaciones principales, con aquellas otras relacionadas con el mismo obligado tributario, pero dicha regulación ha resultado insuficiente. La Ley 34/2025 no ha producido un efecto tan evidente y preciso como hubiera cabido esperar, ni siquiera la definición que ofrece el propio apartado 9 del art 68 LGT de las obligaciones tributarias conexas, dilucida mucho, muy al contrario, de la misma obtenemos términos que generan mayor incertidumbre por su imprecisión (elementos, afectados o se determinen).

Aunque resulta incuestionable que la reforma parcial de la LGT, recoge la regulación de las obligaciones tributarias conexas pensando, sobre todo, en aquellos casos en los que la Administración ha efectuado una regularización que afecta a dos o más periodos impositivos, de forma que el contribuyente, impugna una liquidación relativa a uno de esos periodos, sin perjuicio de las consecuencias de signo contrario que pudieran surgir en los demás. Resultando ,por ende, imprescindible la introducción de la interrupción del plazo de prescripción de los derechos a liquidar y a reconocer una devolución, relativos a las obligaciones tributarias conexas del propio obligado tributario, cuando en éstas se produzca o haya de producirse una tributación distinta como consecuencia de la aplicación de los criterios o elementos en los que se fundamente la regularización de la obligación con la que estén relacionadas las obligaciones tributarias conexas.

A pesar de todo lo expuesto, no podemos dejar constancia de nuestra preocupación existente acerca de esta materia. Quedan todavía muchas incógnitas por resolver. Algunas se irán planteando a lo largo de ejercicios posteriores y, con seguridad, será la propia jurisprudencia la que deberá resolverlos. 


\section{BIBLIOGRAFÍA.}

\section{IX.A. Textos.}

CORDERO GONZÁLEZ, E.: "La interrupción de la prescripción en relación con las obligaciones conexas tras la reforma de la Ley General Tributaria por Ley 34/2015" en Civitas Revista Española de Derecho Financiero, núm. 170, 2016.Págs 1-27.

Falcón y Tella, Ramón; Peña Velasco, Gaspar de la; Simón Acosta, EugEnio Código Tributario, 32 ${ }^{\mathrm{a}}$ Edición (2017) Editorial Aranzadi. Págs. 97-103, págs. 138-142, págs. 178-183, págs. 229-242.

García Díez, Claudio; Mallada Fernández, Covadonga; Sánchez Pedroche, José Andrés. "Derecho tributario. Procedimientos tributarios". $2^{\text {a }}$ Edición, UDIMA (Universidad a Distancia de Madrid) Ediciones CEF. -2016. Pág.360 - 600.

TEJERIZo LóPEz, J.M.: "La prescripción en materia tributaria, especial referencia a la eficacia de su interrupción respecto de las obligaciones conexas", UNED-AEDAF, 2016. Pág. 3-12.

CREMADES Schulz, M.: "Las obligaciones conexas antes de la Reforma de la Ley General Tributaria por la Ley 34/2015", en Actualidad Jurídica Uría-Menéndez, núm. 42, 2016. Pág. 115-120.

Martín Queralt, Juan; Lozano Serrano, Carmelo; Tejerizo López, José María; Casado Ollero, Gabriel" Curso de derecho financiero y tributario" Edición $28^{\text {a }}$. Lección 11 pág. 354, lección 12, pág. 394-395 y 422-424.Lección 13, págs.449-461 y pás.482-506. Lección 17. Pág.709-729.

AA.VV.: "La interrupción de la prescripción en relación con las obligaciones conexas tras la reforma de la Ley General Tributaria por Ley 34/2015", en Boletín Jurídico Gestión Tributaria Territorial, 22 de julio de 2016. Pág. 1-27.

EsEVerRi Martínez, E., "La prescripción tributaria (nueva regulación)", en C. García-Herrera Blanco (cord.) IV encuentro de Derecho Financiero y Tributario $\left(1^{a}\right.$ parte), en Documentos de Trabajo del IEF, núm. 13, 2016:

El plazo de duración de las actuaciones inspectoras tras la reforma de la Ley General Tributaria introducida por la Ley 34/2015, de 21 de septiembre, por CALVO VÉRGEZ, JUAN (Universidad de Extremadura). Pág.17. 
Retroacción de actuaciones y actuaciones de ejecución, por MIGUEL CANUTO, ENRIQUE DE (Universitat de Valencia). Pág.45-57.

La prescripción tributaria (nueva regulación), por ESEVERRI, ERNESTO (Universidad de Granada). Pág.69-77.

La nueva ejecución de resoluciones económico-administrativas, por GARCÍA SARABIA, FRANCISCO DE ASÍS (Universidad Católica San Antonio de Murcia). Pág.91-101.

La prescripción del derecho a solicitar devoluciones tributarias en la reforma de la Ley 34/2015, por GOROSPE OVIEDO, JUAN IGNACIO (Universidad San Pablo-CEU) Págs.103-106.

La prescripción del derecho a solicitar devoluciones tributarias en la reforma de la Ley 34/2015, por GOROSPE OVIEDO, JUAN IGNACIO (Universidad San Pablo-CEU). Pág.104-113.

Consideraciones en torno al plazo de terminación de los procedimientos de gestión tributaria, por MANZANO SILVA, ELENA (Universidad de Extremadura). Pág.127-136.

Consideraciones sobre la reforma de la Ley General Tributaria en materia de revisión en vía administrativa, por MORENO GONZÁLEZ, SATURNINA (Universidad de Castilla-La Mancha). Pág.167-185.

La comprobación de ejercicios prescritos y la seguridad jurídica, por SOTO BERNABEU, LAURA (Universidad de Alicante). Pág.249-257.

GÓMEZ TABOADA, J.: "Las obligaciones tributarias conexas han venido para quedarse”, en El notario del siglo XXI, núm. 69, 2016. Pág. 1 y 2.

Gómez TABOADA, J:" El envés de las obligaciones conexas ¿victoria del orden o derrota de la justicia?" Documentos - Instituto de Estudios Fiscales, ISSN 1578-0244, No. 19, 2015, págs. 50-60.

\section{IX.B. Materiales telemáticos.}

Análisis de Impacto Normativo. Impacto en cargas administrativas, recuperado de: http://www.mptfp.es/portal/funcionpublica/gobernanza-publica/simplificacion/impacto-normativo.html

Aspectos Relevantes de la Reforma Tributaria, recuperado de: https:// www.youtube.com/watch?v=eNFDiyEBcD4 ;

https://boletinjuridico.gtt.es/la-interrupcion-de-la-prescripcion-en-relacion-con-las-obligaciones-conexas-tras-la-reforma-de-la-ley-general-tributaria-por-ley-342015/ 
https://canal.uned.es/video/5a6fae31b1111f50318b478c?track_ $\mathrm{id}=5 \mathrm{a} 6 \mathrm{fae} 32 \mathrm{~b} 1111 \mathrm{f} 50318 \mathrm{~b} 478 \mathrm{f}$

https://www.youtube.com/watch?v=M0je-5ju7G0;

La interrupción de la prescripción la relación con las obligaciones conexas tras la reforma de la Ley General Tributaria por Ley 34/2015, recuperado de:

La prescripción en la nueva Ley General Tributaria, recuperado de: https:/www.youtube.com/watch?v=vdiwdibvMC4.

Reforma del procedimiento de Gestión Tributaria prevista en el Anteproyecto de modificación de la Ley General Tributaria , recuperado de https://canal.uned.es/video/5a6f6baab1111fc3498b4575

\section{IX.C. Revistas.}

CORDERo GonZÁLEZ, E. M ${ }^{\mathrm{a}}$.” La interrupción de la prescripción en relación con las obligaciones conexas tras la reforma de la Ley General Tributaria por Ley 34/2015". Revista española de Derecho Financiero num.170/2016 parte Estudios Editorial Civitas, SA, Pamplona. 2016. BIB 2016 2649. Págs.1-27.

Gómez TABOADA. J. "Las obligaciones tributarias conexas han venido para quedarse” Revista 63, Práctica Jurídica. Pág. 3. 
